\title{
Konsep Pendidikan Akhlak Anak Dalam Islam (Studi Analisis Kitab Taisirul Khollaq Karya Al-Hafizh Hasan Al- Mas'uudi)
}

Mujib Hardianto ${ }^{1}$, Syamsuddin ${ }^{2}$

${ }^{1,2}$ Program Studi Pendidikan Agama Islam, Universitas Hasyim Asy’ari, Indonesia

\begin{tabular}{|c|c|}
\hline Article Info & ABSTRACT \\
\hline Article history: & \multirow{14}{*}{$\begin{array}{l}\text { Pendidikan akhlak diberikan untuk membimbing dan mendidik anak agar } \\
\text { dapat mencapai tujuan hidupnya, yakni menumbuhkan kesadarannya sebagai } \\
\text { manusia sebagai makhluk Allah Swt. agar berakhlak mulia, saat ini, maka } \\
\text { pendidikan akhlak dianggap sangat penting. Dengan adanya kitab Taisirul } \\
\text { Khollaq didalamnya diterangkan permasalahan akhlak secara gamblang } \\
\text {.Adapun fokus penelitian dalam penelitian ini yaitu: 1. Bagaimana konsep } \\
\text { pendidikan akhlak anak dalam Islam? 2. Bagaimana konsep pendidikan akhlak } \\
\text { anak dalam kitab Taisirul Khollaq?. Penelitian ini menggunakan jenis } \\
\text { penelitian kepustakaan (library research). Pendekatan dalam penelitian ini } \\
\text { ialah pendekatan deskriptif analisis.Adapun hasil analisis yang penulis } \\
\text { dapatkan dalam penelitian ini, bahwa konsep pendidikan akhlak anak dalam } \\
\text { kitab Taisirul Khollaq yaitu akhlak kepada Allah SWT. Akhlak terpuji dan } \\
\text { tercela, akhlak terpuji yakni perbuatan dan perkataan terpuji yang mengalir } \\
\text { tanpa merasa terpaksa yang keluar dari diri seseorang. Akhlak terpuji antara } \\
\text { lain; jujur, amanah, murah hati, dermawan, rendah hati, adil, dan lain-lain. } \\
\text { Sedangkan akhlak tercela yaitu perbuatan dan perkataan tercela yang mengalir } \\
\text { dengan merasa terpaksa yang keluar dari diri seseorang. Akhlak tercela antara } \\
\text { lain; bohong, dendam, hasud, menggunjing, adu domba, sombong, dhalim, dan } \\
\text { lain-lain.. Penelitian ini diharapkan dapat membawa manfaat agar semua orang } \\
\text { dapat memiliki akhlak yang baik. }\end{array}$} \\
\hline Received 2019-10-17 & \\
\hline Accepted 2020-02-27 & \\
\hline & \\
\hline & \\
\hline Pendidikan Akhlak & \\
\hline Kitab Taisirul Khollaq & \\
\hline & \\
\hline & \\
\hline & \\
\hline & \\
\hline & \\
\hline & \\
\hline & \\
\hline
\end{tabular}

This is an open access article under the CC BY-SA license.

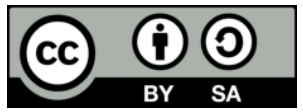

\section{Corresponding Author:}

Mujib Hardianto,

Program studi Pendidikan Agama Islam,

Universitas Hasyim Asy'ari,

Email: Mujibhardi@gmail.com

\section{PENDAHULUAN}

Pendidikan merupakan sesuatu yang dianggap penting dalam kehidupan sehari-hari terutama bagi seorang anak. Pendidikan dalam konsep Islam sering sekali dihubungkan dengan istilah tarbiyyah, ta'lim, ta'dib, riyadhaah, irsyaad, dan tadris. Masing-masing istilah tersebut mempunyai keunikan arti tersendiri ketika sebagian atau seluruhnya disebut secara bersamaan. Namun, kesemuaannya akan memiliki arti yang samaa jika disebutkan salah satunya, sebab salah satu istilah itu sebenarnya mewakili istilah yang lain. Sasaran pendidikan adalah manusia, didalamnya terdapat banyak aspek dan sifat yang sangat lengkap. Karena sifatnya yang lengkap itu, maka tidak sebuah batasan cukup untuk menjelaskan makna pendidikan secara lengkap. Batasan tentang pendidikan yang dibuat oleh para ahli bermacam-macam, dan isinya tidak sama antara yang satuu dengan yang lainnya. Perbedaan tersebut mungkin karena orientasinya, konsep dasar yang dipakai, aspek yang menjadi tekanan, namun yang terpenting adalah bagaimana pelajar menyesuaikan diri dan menempatkan diri dengan sebaik-baiknyaa dalam menjalin hubungan dengan semua ituu dan dengan siapapun itu. Kita sering sekali mendengar istilah akhlak di tengaah-tengah kehidupan kita. Mungkin hampir semua orang mengetahui arti kataa "akhlak" karena kata akhlak sering dihubungkan 
dengan perilaku manusia. Akan tetapi, supaya lebih jelas dan lebih meyaakinkan, kata "akhlak" masih perlu untuk didefinisikan secara bahasa maupun istilah. Dengan demikian, pemahaman terhadap kata "akhlak" tidak hanya sekedar kebiasaan praktis yang sering kita dengar, tetapi sekaligus dipahami secara filosofis, terutama makna sebenarnya. Dalam bahasa kitaa sehari-hari akhlaq diartikan sebagai budi pekerti. Istilah budi pekerrti berasal dari bahasa Sansakerta dalam bentuk isim fi'il sedangkan mashdarnya budi: artinyaa kesadaraan. Bentuk maf'uul budha artinya disadarkan/saadar kembali (ingat sejarah Budha Gautamaa). Sedang pekerti diartikan dengan perangai/kelakuan/tingkah laku. Jadi budi pekerti didefinisikan dengan kesadaran dalam bertingkah laaku atau perbuuatan/tindakaan manusia yang dilakukaan secara sadar.

Dalam bahasa Inggris akhlak atau budi pekerti dikenal dengan sebutan Ethica berasal dari bahasa Yunani ethos artinya moraal dari bahasa latin mores yang diartikan dengan adat atau kebiasaan yang baik sesuai dengan nilai-nilai kemanusiaan yang berlaku. Sekalipun Akhlakul Islam dapat diterjemahkan dengan Ethica Islam atau Moral Islam, tetapi sinonim itu hanyalah batasan bahasa yang tidak dalam makna sebenarnya karena istilah ethica atau moral dalam istilah Barat tidak mengenal dimensi hubungan akhlak manusia terhadap Tuhan (tasawwuf). Akhlak digambarkan sebagai sikap yang darinya akan tumbuh kemampuuan untuk memberi tanggappan secara respoonsif (tanpaa dipikir terlebih dulu) terhadap suatu nilai, karena sikaap ituu telah mendaraah daging/menjadi tabiat yang diperoleh dari kebiasaan yang berulang-ulang melalui proses latihan.

Dari pemaparan diatas peneliti merasa tertarik untuk mencoba meneliti dan mengetahui tentang penerapan konsep pendidikan akhlak anak dalam Islam. Oleh karena itu peneliti ingin mencoba mengkaji lebih dalam kitab Taisirul Khollaq dengan mengambil juduul penelitian Konsep Pendidikan Akhlaq Anak Dalam Islam (Studi Analisis Kitab Taisirul Kholaq Karyaa Hafidh Haasan Al-Mas'udi) dalam rangka untuuk memberikan penjelasan tentang penerapan konsep pendidikan akhlak anak dalam Islam agar mempunyai budi pekerti yang mulia seperti Rasulullah Muhammad SAW. Fokus pada penelitian ini adalah: (1) Bagaimanaa konsep pendidikan akhlaq anak dalaam Islam? (2) Bagaimanaa konsep pendidikan akhlaq anak dalam kitab Taisirul Khollaq? Berangkat dari konteks dan fokus penelitian di atas, maka dapat ditetapkan beberapa tujuan penelitian sebagai berikut: (1) Untuk mengetahui dan memperoleh kejelasan tentang konsep pendidikan akhlak anak dalam Islam. (2) Untuk mengetahui dan memperoleh kejelasan tentang konsep pendidikan akhlak dalam kitab Taisirul Khollaq.

\section{Kajian Pustaka}

Istilaah akhlaq sudah sangatt akrab di dalam kehidupan kita sehari-hari. Mungkin hampir semua orang mengetahui arti kata "akhlak" karena perkataann akhlaq selaalu dihubungkan dengan perilaku manusiaa. Akan tetapi, agar lebih jelaas dan meyakinkan, kataa "akhlak" masih perluu untuk diartikan secaraa bahasa maupun istilaah. Dengan demikian, pemahaaman terhaadap kata "akhlak" tidak sebatas kebiasaaan praktis yang setiap haari kita dengaar, tetapi sekaliguus dipahami secaara filosofis, terutama maknaa substansinya. Kata "akhlak" berasal dari bahasa Arob, yakni jamaknya kata "khuluqun" yang secaraa bahasa berarti budi pekerti, perangaai, tingkah lakuu atau tabiaat, tata kramaa, sopan santuun, adaab, dan perilaku. Kaata "akhlak" juga berasal dari kata "khalaqo" atau "khalqun", artinyaa kejadian, yang berhubungan eratt dengaan "Khaliq", artinyaa mencipptakan, tindaakan atau perbuaatan, sebagaimana terdapat kata "alkhaliq", artinyaa yang menpenciptakan dan "makhluk", artinyaa yang diciptaakan.

Menurut Ibnu Maskawaih, yang terkenal sebagaai paakar bidang akhlaq termuka berkata bahwa akhlaq yaitu sifat yang tertanaam pada jiwa seseorang yang mendorongnya untuuk melakukaan perbuatann tanpaa memerlukaan pemikiran serta pertimbanngan terlebih dahulu. Sementara itu, menurut Imaam Al-Ghozali, yang dikenal sebagai hujjatul Islaam (pembelaa Islaam) karena keberhasilannya dalaam membela agama Islam dari berbagai pahaam yang dianggap menyesatkaan, mengatakann bahwaa akhlaq ialah sifaat yang tertaanam daalam jiwa seseorang yang menimbulkan berbagai macam perbuataan taanpa memerlukaan pemikiran dan pertimbaangan terlebih dulu.

Sedangkan menuruut DR Ahmad Amin akhlaq ialah kemauan yang selalu terulang sehingga kemudian menjadi kepribadian yang melekat pada dirinya. Menurut Ahmad bin Mustofa akhlaq yaitu ilmuu yang darinya kita bisa mengetahui jenis-jenis keutaamaan dan keuutamaan itu ialah terwujudnyaa keseimbaangan antaara tiga kekuaatan; kekuatan berpikir, kekuaatan maarah, dan kekuuatan syahwatt. Sementara menurutt Muhammad bin Ali Asy-Syarif Al-Jurjani akhlaq adalah suatu sifat (baik atau buuruk) yang tertanaam kuat dalaam diri yang darinya muncul perbuatan-perbuaatan deengan mudaah dan ringan tanpaa perlu berpikir dan mereenung. Konsep akhlaq dalaam Al-Qur'an salah satunyaa, diambil dari pemahaaman terhadap surat Al-'Alaaq ayat 1-5, yang secaara tekstuaal menyatakaan Allah SWT menciptakaan manusia sekaligus membebaskaan manusia dari kebodoohan ('allamal insaana maalam ya'lam).

Ayat pertaama surat Al-Alaaq tersebutmenjadi penentu perjalanaan akhlaq manusia karenaa ayat tersebut menjelaskan agar setiap tindakaan harus dimulai dengan keyakinan yang kuaat kepada Allaah SWT sebagai Pencipta semuaa perbuatan atau yang memberi kekuataan untuk berakhlaq. Kata "rabbun" pada 
ayat (bismirabbik) diartikan akhlaq harus didasarrkan padaa pengetahuaan tentang ketuhanan. Kata "rabbun" berasal dari kataa "rabba yarubbu tarbiyyatan". Oleh karena ituu, makna akhlaq memiliki karakteristik berikuut:

(a) Akhlaq dilandasi oleh nilai-nilaai pengetahuaan ketuhanan.

(b) Akhlaq dilandasi oleh nilai-nilai kemaanusiaan.

(c) Akhlaq dilandasi oleh ilmu pengetahuaan.

\section{METODE}

Penelitian ini menggunakan jenis penelitian kualitatif. Penelitiaan kualitatif menurut pendapat Bog dan dan Taylor dalam S. Margono yakni proses penelitian yang bisa menghasilkaan dataa deskriptif berupaa kata-kataa tertulis dari orang yang diwawancarai atau perilakuu orang yang diamati secara alamiah untuk dimaknai atau dianalisis. Jenis penelitian dalam penelitian ini adalah Library Reseach atau sering disebut dengan penelitian kepustakaan. Penelitian kepustakaan (Library Reseach) merupakan penelitian yang memfokuskan pada proses menganalisis atau menafsirkan bahan tertulis berdasarkan dengan konteksnya. (Adnan Mahdi Mujahidin, 2014).

Adapun pendekaatan yang digunakaan dalam penelitian ini adalah pendekaatan deskriptif analisis. Deskriptif ialah data-dataa yang dikumpulkaan yaitu berupa kata-kaata, gambar, dan bukan angka-angkaa. Dan semua data yang telah dikumpulkan berkemungkinan menjadi kunci terhadap apa yang sudah diteliti (Lexy J Moleong, 2016). Dengan demikian dalam penelitian ini, peneliti berusaha memaparkan atau menggambarkan konsep pendidikan akhlaq dalaam Kitab Taisirul Kholak Karya Hafidh Haasan AlMas'udi. Dalam penelitian ini, sumber data primer yang digunakan yaitu Kitab Taisirul Kholak Karya Hafidh Hasan Al-Mas'udi Dan adapuun data sekunder yang digunakan dalam penelitian ini adalah buku terjemah dan buku lain yang membahas mengenai penelitian dalam jurnal ini.

Teknik pengumpulan daata yang penulis gunakan dalaam penelitian ini ialah dokumentasi atau sering disebut penelitian dokumentasi (Documentary Reseach) atau survey buku (Book survey reseach). (Mahmud, 2010). Dokumen merupakan rekaman-rekamaan akan kejadiaan masa lalu yang ditulis atau dicetak, dapat berupaa catatan,buku harian, surat dan dokumen-dokumen. (Djam'an Satori, 2014). Dalam penelitian ini, peneliti mencari data-data dan buku catatan tentang konsep pendidikan akhlak dalam Islam. Selanjutnya data yang diperoleh kemudian dianalisis dengan Analisis deskriptif, yaitu menggambarkan bagaimana konsep pendidikan akhlaq dalam Kitab Taisirul Kholak Karya Hafidh Hasaan Al-Mas'uudi secara sistematis. Tahap berikutnya adalah interpretasi, yaitu memahami seluruh konsep pendidikan Kitab Taisirul Kholak Karyaa Hafidh Hasaan Al-Mas'udi untuk mendapatkan kejelasan yang terkandung di dalamnya.

\section{HASIL DAN PEMBAHASAN}

\section{Profil al-Hafizh Hasan al-Mas'uudi}

Nama lengkapnya adalah al-Hafizh Hasan Al-Mas'udi adalah Abul Hasan Ali bin Husein bin Ali AlMas'udi atau Abul Hasan Ali bin Husein bin Abdulloh Al-Mas'udi. Beliau dilahirkan di kota Baghdad-Iraq menjelaang akhir abad ke $9 \mathrm{M}$. Beliau wafat di Fustat (Mesir) paada tahun 345 H/956 M. Pernyataan ini sama dengaan pernyaataan dalam Ad-Dhahabi dan surat tulisan Al-Mushabi yang menyatakan Al-Mas'udi meninggal dunia pada bulan Jumadil Akhir tahun $345 \mathrm{M}$. Beliau terkenal dengan sebutan Al-Mas'udi. Beliau keturunaan Arab yaitu keturunan Abdulloh bin Mas'udi seorang sahabat Nabi Muhammad SAW yang dihormati.

Mas'udi dilahirkan di kota Baghdad. Pada masa mudanyaa, dia sangat menguasaai ilmu sastraa dan juga berbagai ilmu pengetahuaan lainnya. Namun, bidang kajiannya yang hakiki yakni pengembaraannya yang luaas di darat dan di laut yang mencaakup negeri India hinggaa lautan Atlantik, dari laut Meraah hingga laut Kaspia. Bahkan ada kemungkinan dia telah mengembara sampai ke Cina dan kepulauan Melaayu. Setelah menyelesaikan pendidikan pertama yang ia terima dari ayahnya, Al-Mas'udi segera berencana untuk mendalami sejarah, adat istiaadat, kebiasaan, dan cara hidup penduduk disetiap negeri. Ia juga banyak mempelajaari ajaran Kristen dan Yahudi, serta sejarah Barat dan Timur yang berlaatar belakaang Kristen dan Yahudi.

Pengembaaraan Intelektuaalnya dimulai dengan mengunjungi negeri Iran dan Kirman (915). Beliau juga pernah bermukim di Ushtukhar, Persia dan dari sanaa kemudian pergi ke India, mengunjungi Multan dan Al-Manshuro. Bersamaa para pedagang, ia melanjuutkan pengembaraannyaa ke Ceylon (Srilanka) dan ia ikut mengarungi laut Cina. Dalam perjalanan pulang ia mengelilingi Samudera Hindia dan kemudian mengunjungi Omaan, Zanzibaar, pesisir Afrika Timur, Sudaan, dan Madagaskar. Pada tahun 926 M ia 
kembali mengadakaan perjalaanan ke beberapa negeri seperti Tiberias (Suriah) dan Palestina, serta tahun 943 M ke Antioch (Suriah). Ia juga mengelilingi negeri-negeri Irak dan Arab Selatan. Sepuluh tahun terakhir hidupnya dilalui di Suriahdan kemudiaan di Mesir, tempat ia meninggal dunia.

\section{Konsep Pendidikaan Akhlak Dalam Kitab Taisirul Khollaq Karya Hafidh Hasan Al-Mas'udi}

Pertama, Takwa. Akhlak pertama yang terdapat pada kitab Taisirul Khollaq yakni akhlak kepada Allaah SWT. Dijelaaskan didalamnya bahwa berakhlak kepada Allah dapat dilaksanaakan dengan cara bertakwa kepada Allah, yakni melaksanaakan segala perintaah Allah SWT dan menjauhi segala laranganNya baik secara rahasia maupun terang-terangaan. Kedua, Tata Krama Seorang Guru. Guru ialah orang yang mempunyaai kesempurnaan ilmuu dan orang yang bisa mengerti akan keadaan murid, guru harus mempunyai sifat terpuji yang mana akan berpengaaruh kepada murid serta guru juga menjadi penentu bagi murid yang mana keberhasilaan murid itu ada padaa gurunyaa. Guru sebaiknyaa bersifat sopan santuun, penyabar, pengasih, penyaayang, lemah lembuut, dan lain-lain agar tabiatnya atau akhlaknya bisa dikuti muridnya serta mereka bergairah menerima segala petunjuk yang datang darinya. Seorang guru hendaknya selalu menasehati, mendidik, membimbing, mengarahkan, dan memotivasi murid-muridnya dengan baik dan benar, jangan sampai ia membebani murid-muridnya dengan segalaa sesuatu yang mereeka belum mengerti dan pahami. Adab seorang pendidik (guru) itu ada dua macam: Adab seorang pendidik (guru) terhadap dirinya sendiri. Adab seorang pendidik (guru) terhadap murid-muridnya.

Ketiga, Tata Kramaa Seorang Murid. Menjadi seorang murid harus mempunyai tata krama terhadaap dirinyaa sendiri, gurunya maupun saudara-saudaranya. Adapun tata kraama terhadap dirinya sendiri, diantaranyaa: Pertama, Memeliharaa diri sendiri hal ini diwujudkaan dengaan cara tawadhu', tidak somboong dan menjaga seluruh anggoata tubuhnya. Kedua, Hendaknya bersikap dan bertutur kata yang jujur, agar dicintai dan dipercaya teman-temannya. Ketiga, Seharusnya seorang murid bersikap rendah diri ketika berjalaan dan tidak memandaang segala sesuatu yang dilarang oleh Allah SWT. Keempat, Hendaknya seorang murid bersikap jujur dalam pengetahuannya dan tidak menjawaab apa yang tidaak diketahuinya.

Adapun cara bertata krama dengan gurunya, diantaranya: Pertama, Adab kepaada guru sebagai murid yang mempunyaai adab yang baaik harus mempercayaai bahwa guru itu lebih utama dari pada kedua orang tua, sopan santun kepaada guru baik di depan maupun di belakangnyaa, tidak memuji guru lain di depan gurunyaa, dan mentaati apa yang sudah diajarkaan oleh gurunya. Kedua, Hendaknya seorang murid duduk dengan sopan dan baik, mendengarkan penjelasan guru ketika mengajar dengan sopan santun. Ketiga, Hendaknya seorang murid tidak bercanda ketika guru sedang menjelaskan materi atau pelajaran di dalam kelas ketika pelajaran sudah dimulai. Keempat, Seharusnya murid tidak malu bertanya kepada guru tentang apa yang belum ia mengerti dan pahami. Kelima, Hendaknya seorang murid bertutur kata yang sopan ketika berbicara dengan gurunya, jangan berbicara seperti dengan temannya sendiri. Keenam, Hendaknya seorang murid mengucapkan salam dan bersalaman ketika bertemu dengan gurunya kapan pun dan dimana pun dia berada. Ketujuh, Tidak berjaalan di depannyaa, tidak duduk di tempatnyaa, tidak memulaai percakapan dengannyaa kecuali mendapatkan izinnyaa, tidak memperbanyaak omongan di sisinyaa, tidak menanyaakan sesuatu ketika beliau sudah bosan, menjaga waktuu dan tidak mengetuk pintu rumah atau kamarnaya, tetapi harus menunggu sampai beliau keluaar. Kedelapan, Seorang murid harus berusaaha mendapaat ridhonya, menghindaari kemurkaannyaa dan patuh kepadaanya selain dalam perbuatan maksiat kepada Allah SWT, sebab tidak booleh patuh kepada makhluk untuk melakukan perbuaatan maksiat kepada Allah SWT, dan Kesembilan, Menghormati anak-anak guru dan orang yang mempunyai hubungaan dengannyaa.

Keempat, Hak Asasi Ibu Bapak. Orang tua merupakaan salah satuu sebab seoraang anak itu ada dimuka bumi ini yang mana perjuaangan dari orang tua itu tidak akan habis dihitung dengaan cara apapuun, terutamaa seorang ibu yang telah menganduung seoraang anak selama sembilan bulan dan melahirkannya dalam keadaan sulit, dan bapaklah yang bertanggung jawaab atas semua kehidupaan di rumah tanggaa. Setelah anaknya terlahir pun, jerih payah orang tua tidak berhenti sampai disitu. Betapa rasa belas kasih keduanya masih menyelimuti anak. Keduanya berusaha merawat, membimbing, serta memenuhi segala kebutuhan anak sampai benar-benar tumbuh sebagai pribadi yang mandiri. Seluruh waktu, tenaga, pikiran, harta, bahkan jiwa orang tua tercurahkan demi ingin melihat anaknya tercukupi tanpa kekurangan apapun. Seberapa besar rasa lelah orang tua akan hilang hanya dengan melihat anaknya merasa senang. Dengan begitu anak seharusnya berbakti kepada kedua orang tua dan membuaat mereka bahagia.

Hendaklah seorang anak tidaak menentang perintah orang tuanya, kecuali jika diperintah untuk melakukan maksiat. Dan seorang anak seharusnya duduk dihadapaan keduanya sambil menundukkaan kepala dan menutup pandangaan matanyaa dari berbagai kekurangaan kedua orang tua. Jangan pernah menyakiti orang tuanya, walaupun dengan ucapan sekecil apapun, apa lagi membatah keduanya. Dan seharusnya seorang anak tidak berjalaan di depan keduanyaa, kecuali untuk mengabdi kepada orang tuanya. Hendaaknya seorang anak selalu mendoakan orang tuanya dan menyuruh ibu bapaknya berbuat amar 
ma'ruf nahi munkar, agar keduanya terhindar dari siksa api neraka, sebab keduanya adalah penyebab kelahiran anak di dunia.

Kelima, Hak Asasi Kaum Kerabat. Dalam hubuungan saudaraa semua dianggaap keluargaa dan peliharaalah hubungaan persaudaaraan. Bahkaan Allah SWT dan utusan-Nya memerintahkan untuk memeliharaa tali persaudaaraan dan melaraang untuk memuutus tali persauudaraan. Sebaiknya seorang bersikap rendah hati kepada kaum kerabatnyaa, bersaabar terhadap keburuukan mereka, walaupun merekaa sudah melampaui bataas terhadapnya. Sebagai orang muslim sepatutnya menolong seorang dari kerabatnya apabila mendapat ujian, cobaan, musibah agar beban yang dihadapi semakin ringan dan cepat selesai. Karena sesungguhnya Allah SWT akan selalu menolong hamba selama ia menolong saudaranya.

Keenam, Hak Asasi Tetangga. Tetanggaa ialah orang yang bertempaat tinggaal paling dekat dengan kita, maka kita harus menghargai mereka, dan saling menolong mereeka. Ketujuh, Tata Krama Pergaulan Di dalaam pergaaulan kita dianjurkaan berwaajah ceria, setiaa kawan, menghargai pendaapat orang lain, rendaah hati dan tidak somboong. Lebih baik berdiam jikaa temaan bergurau, memintaa maaf dan memaafkaan jika mempunyai kesalaahan kepaada teman. Sebaiknya kita tidak membanggaakan keduduukan dan kekaayaan, karena hal itu bisa menyebabkaan nilai, martabat seorang jatuh di mata orang lain. Seharusnya kita menyembunyikan rahasia orang lain, karena seorang tidak ada nilainya jika tidak pandai menyembunyikan segala rahasia. Ada tiga haal yang haruus dipegang oleh manusia yaitu: dapaat dipercaaya, dermaawan, dan tidaak membukaa aib seseoraang.

Kedelapan, Kerukunan. Kerukuunan merupakan raasa kebersaamaan dan persaudaaraan antara seoraang dengaan orang banyak yang maana masing-masing individunyaa saling bergembiraa ketika bertemuu dengan sesamanyaa. Sedangkaan manfaat dari rasa kasih sayaang dalaam persauudaraan yaitu timbulnaya rasa simpati, toloong menolong dalaam kebaikan dan takwa yang pada akhirnyaa segala permaasalahan menjadi gampang dan bebaannya berkuraang karena dikerjakan bersaama-sama dan saling bantu-membantuu. Kesembilan. Persaudaraan. Persaudaaraan secaara mudah bisat diartikan menjaadi ikaatan kuat di antaara dua orang yang kemudian menjaadi rasa persaudaraan antaraa keduuanya. Kedua oraang yang saling bersaudaara dianjurkaan saling berbuat baik, berikutnya saling toloong menoolong satu dengaan yang lain, saling memaafkan kesalaahan satu samaa lain, saling mencegaah kemungkaran antara keduaanya, saling mengaajak kepada kebaikan, dan tidak kalah penting ialah mempertahannkan ikataan tali persauudaraannya. Terlepas dari semuaa itu, mannfaat ikaatan persaudaraan sangatlah luas, manusia diciptaakan dengan karaakter sosial tinggi sehinggaa ikaatan persaudaraan menjadi sangaat penting untuk menompang hubungan tersebut. Kesimpulannyaa sebagai seorang muslim wajib menjaaga tali persaudaaraan antara keraabat, keluaarga dan saudaara serta sesamaa muslim pada umumnya.

\section{Konsep Pendidikan Akhlak Anak Dalam Islam}

Telah diketahui bahwa akhlak yang baik itu berpangkal: (1) kepada kesetabilan kekuatan akal dan kesempurnaan hikmah (ilmu), (2) kepada kesetabilan kekuatan ghadhob (marah) dan syahwat, di mana kekuatan ghadhob dan syahwat itu selalu mentaati petunjuk akal dan syarak. Sedangkan kesetabilan ini dapat berhasil dengan dua cara.

Pertama, dengan جود إلهي(sifat dermawan pemberian Allah) dansesempurnaan yang alami), karena manusiaa itu diciptaakan dan dilahirkan dengaan sempurnaa akalnyaa juga baik perangainya, terjaga dari kekuatan syahwat dan ghadhob. Bahkan syahwat dan ghadhob itu diciptakan dalam keaadaan stabil dan tunduk pada akal dan syara'. Sehingga manusia itu dapat menjadi alim taanpa belaajar, terdidik tanpaa dididik, seperti Nabi Isa bin Maryaam dan Nabi Yahyaa bin Zakariaa 'alaihimas salam, begitu pula nabinabi yang lain shalawatullahi 'alaihi ajma'in.Kedua, berusaha memperoleh budi pekerti ini dengan mujahadah (memerangi nafsu) dan riyadhoh (melatihnya). Yakni, mendorong jiwa untuk mengerjakan perbuatan-perbuatan yang sesuai dengan tuntunan akhlak yang mulia. Maka, barang siapa yang ingin agar dirinya memiliki rbudi pekerti yang dermawan, maka caranya adalah memaksakan diri untuk melakukan perbuatan orang-orang yang dermawan, yakni dengan menyerahkan hartanya kepada orang lain.

\section{KESIMPULAN}

Berdasarkan uraian diatas, penulis dapat menyimpulkan bahwa: pertama, Akhlak kesatu yang adaa dalam kitab Taisirul Khollaq yakni akhlak kepadaa Allah SWT. Dijelaskaan di dalamnyaa bahwa berakhlak terhadap Allah bisa dilaksanaakan dengaan caara bertakwa kepada Allah, dalaam ari takwa itu sendiri yakni mengerjakan semuua perintah-Nya dan meninggalkan semua laraangan-Nya, baik dalaam keadaan sepi atau ramaai. Keberhasilan takwa bisa dilaksanakaan dengaan menanamkaan perkaraa yang baik dan menghindarri daaari perkara yang buruuk. Adab guruu dan murid, guruu ialah orang yang mempunyai kesempurrnaan ilmuu dan oraang yang bisa mengerti akan keadaan murid. Sedangkaan murid mempunyai mempunyai kewajiban untukk menghormaiti guru daan menghormati kepadaa sesaama teman.-temannyaa. 
Kedua, Akhlak terpuji dan terceela, akhlak terpuuji yaitu perbuaatan serta perkaataan terpuji yang mengalir tanpaa meraasa terpakksa yang keluaar dari diri seseoraang. Akhlak terpuji antaraa lain; jujuur, amaanah, murah hati, dermaawan, rendah hati, adil, dan lainn-lain. Sedaangkan akhlak terceela yakni perbuaatan dann perkaataan terceela yang mengalir dengan merasaa terpaksaa yaang keluarr dari diri seseoranng. Akhlak tercella antaara lain; dusata, denddam, hasuud, menggunjing, aduu domba, sommbong, dhalim, dan laain-lain.

\section{REFERENSI}

Adisusilo, Sutarjoo. 2012. Pembelajaraan Nilai Karaakter. Jakarta: PT Rajaa Grafindoo Persaada.

Ahmad Djamaluddin Muhammad. Pendidikan. Jombang: Pustaka Muhibbin, 2010

Ahmad, Jamil. Seraatus Muslim Terkemukaa. Jakarta: Pustaaka Firdauss, 1994.

Al-Mas'ud, Hafidz Hasan. Taisirul Kholaq Fi'Ilmil Akhlaq, terj. Achmad Sunarto. Surabaya: Al-Miftah, 2012.

Amin, Husain Ahmad. Searatus Tookoh dalaam Sejarahh Islamm. Bandunng: PT

RemajaRosdakarya, 2003.

Arief, Romly Muhammad. Kuliah Akhlak Tasawuf. Jombang: Unhasy Press, 2008

Arikunnto,Suharsimi. Proseedur Penelitian Suatu Pendeekatan Praktik. Jakarta: Rineeka Cipta, 2010

Bungin, Burrhan. Penelitian Kualitatif. Jakartaa: Prenada Media Grouup, 2015.

Dian Dinari, 'Stuudi Kompaarasi Kitaab Taisir al-Khallaq Karya Hafidz

Hasan al-Mas 'udi dan Wasaya al-Aba'li al-Abna' Karya Muhammad

Muhammad, Ahmadd Djamalluddin. Reseep Al-Ghazaali 11 Langkaah Melatih Jiwaa, Membersihkan Akhlakk, sertaa Mengobati Penyakit Hati. Jombang, Pustaaka Muhibbin, 2009

Mujib, Abdull dan Mudzakkir Jusuuf. Ilmu Pendidikaan Islaam. Jakarta: Kencanaa, 2010

Murtiningsih,Wahyu. Biografi Para Imuwan Muslim. Yogyakarta: InsanMadani, 2008

Ramayulis, Ilmu Pendidikan Islaam, (Jakarta: Kalaam Muliaa, 2002), hlmm. 17

Saebani Ahmadd Beni dan Hamid Abdull. Ilmuu Akhlakk. Banduung: Pustaaka Melia, 2010

Sugiono. Metode Penelitian Pendidikan. Bandung: Alfabeta, 2016

Sukmadita, Nanaa Syaoodih. Metoode Penelitian Pendidiakan. Banduung: PT. Remaaja Rosdakarrya, 2008

Syakir al-Iskandar (Studi Analisis Nilai-Nilai Pendidikan Akhlak)', Skripsi. Yogjakarta: UIN SunanKalijaga, 2013.

Thomas, Lickona. Pendidikan Karakter. Bandung: Nusa Media, 20 